\title{
PELATIHAN PENGEMBANGAN MEDIA PEMBELAJARAN STIMULASI SENSORI VISUAL BAGI GURU PAUD DI KECAMATAN BATANG ANAI
}

\author{
Sri Hartati ${ }^{1}$, Zulminiati ${ }^{2}$ \\ Jurusan PG PAUD, Fakultas Ilmu Pendidikan , Universitas Negeri Padang \\ Email : srihartati@gmail.com, zulminiati@gmail.com
}

\begin{abstract}
ABSTRAK
Lembaga Pendidikan Anak Usia Dini (PAUD) merupakan upaya pemerintah untuk memberikan layanan terhadap anak usia dini dalam rangka mengembangkan berbagai aspek perkembangan anak melalui pelaksanaan pendidikan. Pelayanan yang diberikan guru PAUD haruslah pelayanan yang mampu menstimulasi perkembangan anak, salah satunya stimulasi sensori visual anak. Sensori visual anak dapat distimulasi dengan menggunakan media visual yang sesuai. Berdasarkan hasil wawancara dan pengamatan yang pernah penulis lakukan, ditemukan bahwa rata-rata guru PAUD di Kecamatan Batang Anai Kabupaten Padang Pariaman belum memiliki pengetahuan dan keterampilan yang memadai tentang media untuk menstimulasi sensori visual anak. Hal ini menyebabkan perkembangan sensori visual anak menjadi tidak optimal. Berdasarkan alasan tersebut, penulis merasa perlu diberikan pelatihan dalam hal penggunaan media untuk menstimulasi sensori visual anak bagi guru PAUD di Kecamatan Batang Anai, Kabupaten Padang Pariaman. Tujuan dari pelatihan ini ialah agar para guru PAUD di Kecamatan Batang Anai mampu mengembangkan dan menggunakan media untuk menstimulasi sensori visual anak sehingga sensori visual anak berkembang secara optimal. Rencana luaran dari pelaksanaan pelatihan ini ialah guruguru PAUD Kecamatan Batang Anai memiliki wawasan dan keterampilan dalam mengembangkan media untuk menstimulasi perkembangan sensori visual anak.
\end{abstract}

Kata Kunci: PAUD, Media Pembelajaran, Stimulasi Sensori Visual

\begin{abstract}
The Early Childhood Education Institution (PAUD) is a government effort to provide services to early childhood in order to develop various aspects of childent development through the implementation of education. Teachers must be services to stimulate children's development, one of which is children's visual sensory stimulation. Children's visual sensory can be stimulated using appropriate visual media. Based on the results of interviews and observations that the author has done, it was found that the average teacher in Batang Anai District, Padang Pariaman District did not yet have adequate knowledge and skills about the media to stimulate children's visual sensory. This causes children's visual sensory development to be not optimal. Based on these reasons, the authors feel the need to be given training in the use of media to stimulate children's visual sensory for teachers in Batang Anai District, Padang Pariaman Regency. The purpose of this training is for teachers in Batang Anai District to be able to develop and use media to stimulate children's visual sensory, children's visual senses develop optimally. The output plan of the training was that the Batang Anai District teachers had insight and skills in developing media to stimulate children's visual sensory development.
\end{abstract}

Keyword: The Early Childhood Education Institution. Learning Media, Visual Sensory Stimulation

\section{PENDAHULUAN}

Sehubungan

Peraturan

Pemerintah di atas, maka salah satu prinsip pelayanan terhadap anak adalah asah, yaitu dengan memberikan dukungan kepada anak untuk mengembangkan potensi yang ia miliki, seperti dalam hal pengembangan 
kreativitas, motorik halus, kognitif, dan aspek lainnya.Lembaga PAUD diharapkan dapat mengasah pengembangan seluruh potensi anak melalui stimulasi atau ransangan yang sesuai dengan usia dan tujuan pengembangan, serta memberikan nilainilai edukatif bagi anak sebagai bekal pengetahuan, sikap dan keterampilan untuk pengembangan anak selanjutnya.

Sehubungan dengan kebijakan Dirjen PAUDNI, untuk seluruh bentuk layanan PAUD adalah memberikan layanan yang holistik dan integratif. Holistik berarti seluruh kebutuhan peserta didik untuk tumbuh dan berkembang (kesehatan, gizi, pendidikan, pengasuhan dan perlindungan), dilayani dalam lembaga PAUD. Integratif berarti semua lembaga PAUD, melakukan kerjasama dengan lembaga mitra, serta berkoordinasi dengan instansi-instansi terkait.

Keberhasilan pelaksanaan pendidikan di Lembaga PAUD tidak pula terlepas dari peran guru-guru PAUD. Guru merupakan subsistem penting dan utama dalam peningkatan mutu pendidikan terhadap anak usia dini. Di tangan guru lah hasil pembelajaran dari perkembangan berbagai potensi anak, yang merupakan salah satu indikator mutu pendidikan lebih banyak ditentukan. Tanpa guru yang professional, dan memiliki tentang wawasan terhadap perkembangan anak, akan sulit rasanya sistem pendidikan anak usia dini dapat mencapai hasil optimal sebagaimana yang diharapkan. Oleh Karena itu, prasyarat utama yang harus dipenuhi bagi berlangsungnya proses pembelajaran yang menjamin optimalisasi hasil pembelajaran adalah tersedianya guru PAUD dengan kualifikasi dan kompetensi yang mampu memenuhi tuntutan tugasnya sebagai tega pendidikdi Lembaga PAUD.

Pelayanan yang harus diberikan guru di Lembaga PAUD haruslah pelayanan yang menstimulasi perkembangan anak, salah satunya stimulasi terhadap sensori anak. Sensori anak perlu diberkan stimulasi yang optimal dikarenakan anak memperoleh pengetahuannya melalui sensorinya. Mulyasa (2012:33) menyatakan bahwa pembelajaran hendaknya memberikan stimulasi yang dapat meransang setiap sensori anak secara optimal, sebab setiap sensori anak akan merespon ransangan yang diterimanya, yang nanti akan menjadi pengetahuan baru bagi anak.

Berdasarkan dua pendapat diatas, diketahui bahwa anak rentang usia 0-2 tahun pertama kali anak memperoleh pengetahuannya melalui sensori motorisnya, yaitu meraba, mencium, mendengar, melihat, dan merasakan segala sesuatu yang datang dari lingkungannya. Sensori anak yang pertama kali perlu diberikan stimulasi ialah visual anak. Sebab alat indra tang pertama kali digunakan anak untuk memperoleh pengetahuan baru ialah melalui kegiatan visual. Oleh karena itu guru di Lembaga PAUD haruslah memberikan stimulasi terhadap sensori visual anak melalui kegiatan bermain yang dilaksanakan. 

GURU PAUD DI KECAMATAN BATANG ANAI. Early Childhood Vol. 2 No. 2b, November 2018

Salah satu cara yang dilakukan guru PAUD untuk mempermudah dalam menstimulasi sensori visual anak ialah melalui media. Media yang digunakan dapat melalui alat permainan edukatif ataupun media yang dibuat guru PAUD yang memenuhi standar media pembelajaran untuk anak. Guru PAUD haruslah memiliki pemahaman dan keterampilan tentang penggunaan media sehingga dapat membantu dalam memberikan stimulasi sensori visual anak.

Besarnya pengaruh Lembaga PAUD terhadap perkembangan anak usia dini, maka dari itu pemerintah di provinsi Sumatera Barat telah menerapkan program "Satu jorong satu PAUD". Hal ini dilakukan agar tercukupinya ketersediaan lembaga PAUD untuk pengembangan kemampuan Anak Usia Dini. Berdasarkan data hasil statistik Kemendikbud Tahun 2016/2017, Jumlah TK sebanyak 2.238 sekolah dan Jumlah KB, TPA, dan SPS sebanyak 2.777 sekolah.

\section{Pemerintahan Kabupaten}

Padang Pariaman merupakan salah satu pemerintah yang memiliki perhatian serius terhadap perkembangan Lembaga PAUD. Hal ini di buktikan dengan jumlah lembaga PAUD sebanyak 392 sekolah, jumlah Jika dilihat dari data diatas, Lembaga PAUD di Kabupaten Padang Pariaman berkembang cukup pesat.

Berdasarkan hasil wawancara dan pengamatan yang pernah penulis lakukan di salah satu kecamatan di
Kabupaten Padang Pariaman, ditemukan bahwa rata-rata guru PAUD di Kecamatan Batang AnaiKabupaten Padang Pariamanbelum memiliki pengetahuanyang memadaitentang mediauntuk menstimulasi sensori visual anak.Kurangnya pengetahuan guru tentang penggunaan media untuk menstimulasi sensori visual anak berdampak terhadap ketercapaian perkembangansensori visual anak, dimana perkembangan sensori visual anak menjadi tidak optimal.

Sebagai upaya untuk mengatasi permasalahan di atas, maka guru-guru harus memiliki wawasan pengetahuan dan keterampilan dalam membuat dan menggunakan media untuk menstimulasi sensorivisual anak. Berdasarkan alasan tersebut, penulis merasa perlu diberikan pelatihan dalam hal penggunaan media untukmenstimulasi sensori bagi guruguru PAUD di Kecamatan Batang Anai Kabupaten Padang Pariaman melalui kegiatan pengabdian masyarakat. Sehingga harapan penulis untuk kedepannya, para guru PAUD di Kecamatan Batang Anai mampu membuat dan menggunakan media untuk menstimulasi sensori visual anak sehingga sensori visual anak dapat berkembang secara optimal.

\section{METODE PENELITIAN}

Kegiatan dilaksanakan di Kantor Camat, kecamatan Batang Anai Kabupaten Padang Pariaman yang juga berperan sebagai mitra penulis dalam kegiatan ini. Kegiatan dilaksanakan pada tanggal $8,9,11,12,15$, dan 16 
September 2018. Sasaran pendidikan dan pelatihan ini adalah pendidik PAUDNI di kecamatan Batang Anai Kabupaten Padang Pariaman, dengan kualifikasi pendidikan PGTK/PGPAUD (DIII dan S1). Beberapa pihak yang dilibatkan dalam kegiatan ini, antara lain: Pendidik PAUD di Kecamatan Batang Anai Kabupaten, Staf pengajar program studi PG-PAUD FIP Universitas Negeri Padang, Mahasiswa Jurusan PG-PAUD FIP Universitas Negeri Padang, Ketua PAUDNI Kecamatan Batang Anai Kabupaten Padang Pariaman.

Metode yang digunakan dalam kegiatan pelatihan pengembangan media pembelajaran stimulasi sensori visual bagi guru PAUD di Kecamatan Batang Anai ini adalah metode ceramah (seminar) dan metode praktek, sedangkan untuk program pengayaan dilakukan dengan diskusi kelompok tentang pembuatan media pembelajaran stimulasi sensori visual bagi guru PAUD di Kecamatan Batang Anai. Memberikan pelatihan dengan sesi seminar meliputi 3 materi yaitu. Materi 1, "Lingkungan berkontras", Materi 2, Kartu "bit of intelegence" Memperkenalkan kartu-kartu Bit of Intelligence (Penggal Kecerdasan), kartu-kartu "Bit" adalah data. Kartukartu ini dapat menumbuhkan dan mempertajam jalur penglihatan dan pendengaran bayi dan sekaligus memberinya informasi yang berguna dan menarik secara visual dan intelektual

, Materi 3, "Flashcard". Materi 4, Sesi Simulasi pelaksanaan pembuatan media
Lingkungan berkontras, Kartu "bit of intelegence", Flashcard yang dibimbing langsung oleh narasumber.

\section{HASIL DAN PEMBAHASAN}

Pelatihan diikuti oleh 30 peserta berasal dari para guru PAUD dari beberapa PAUD yang berada di Kecamatan Batang Anai Kabupaten Padang Pariaman. Pelaksanaan pelatihan melibatkan 2 pemateri yang berasal dari program studi yang sama yaitu Pendidikan Guru Pendidikan Anak Usia Dini. Pelatihan yan diberikan kepada para peserta terdiri atas 4 materi pokok yang disampaikan oleh 2 narasumber dalam sesi yang terpisah-pisah. Materi 1, 2, dan 3 disampaikan pada tanggal 8, 9, 11, 12, 15 dan 16 September 2018 sedangkan materi 4 dilaksanakan pada tanggal 12 September 2018. Pelaksanaan pelatihan berlangsung sangat dinamis, antusias, dan bersemangat.

Pemateri 1 dan 2 disampaikan oleh Dra. Zulminiati, M.Pd tentang Lingkungan berkontras, Kartu "bit of intelegence". Sedangkan pemateri 3 dan 4 disampaikan oleh Dra. Sri Hartati, M.Pd tentang Flashcard dan pelaksanaan pembuatan media pembelajaran stimulasi sensori visual bagi guru di PAUD kecamatan Batang Anai. Pelaksanaan pemberian materi tercantum pada Gambar 1 dan Gambar 2 . 
Sri Hartati, Zulminiati. PELATIHAN PENGEMBANGAN MEDIA PEMBELAJARAN STIMULASI SENSORI VISUAL BAGI GURU PAUD DI KECAMATAN BATANG ANAI. Early Childhood Vol. 2 No. 2b, November 2018

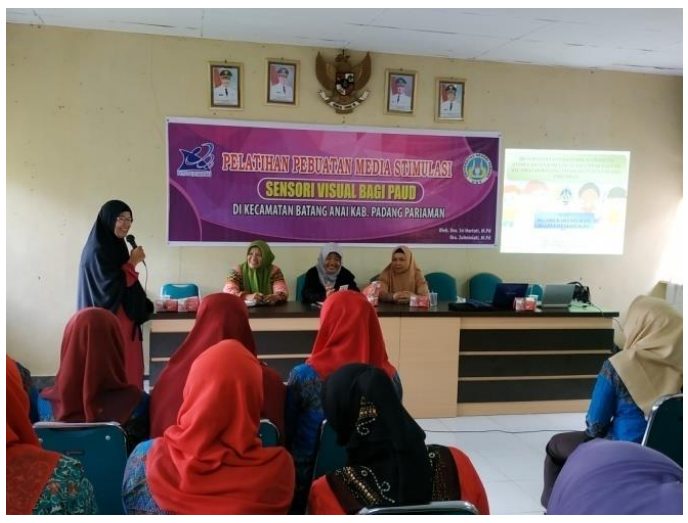

Gambar 1. Pemateri 1 sedang memberikan materi Lingkungan berkontras, Kartu "bit of intelegence".

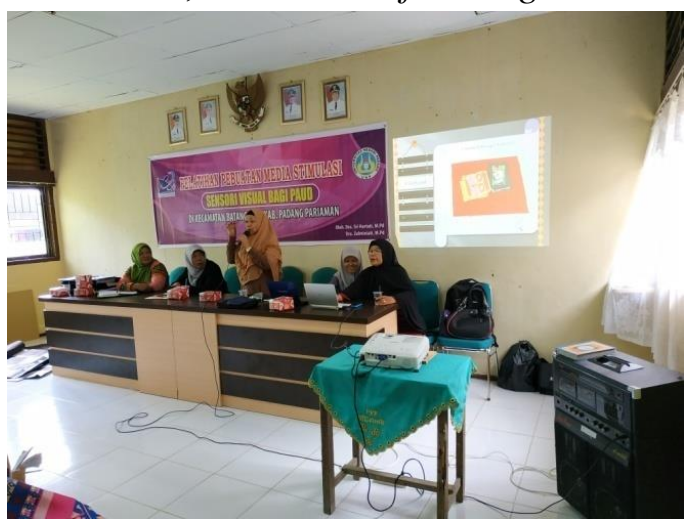

Gambar 2. Pemateri II sedang memberikan materi Flashcard dan pelaksanaan pembuatan media pembelajaran stimulasi sensori visual bagi guru di PAUD.

Gambar 3



Gambar 3. Foto Bersama peserta Pelatihan dengan Panitia dan Pemateri
Tempat pelaksanaan pelatihan yang secara sengaja dilaksanakan di PAUDNI karena PAUD tersebut memiliki ruang serbaguna yang dilengkapi dengan perataan informatika yang menunjang pelaksanaan pelatihan dan ruangan yang luas seperti yang terlihat pada gambar 3. Berdasarkan Gambar 3 juga terlihat keakrapan terjalin meski antara tim pelaksana pelatihan pengembangan dengan para peserta baru sama-sama bertemu. Wajah penuh semangat dan antusias pun jelas tergambar.

Hasil kegiatan pembuatan media pembelajaran stimulasi sensori visual dari 30 orang peserta yang mengikuti pelatihan. Dapat terlihat pada gambar berikut ini:

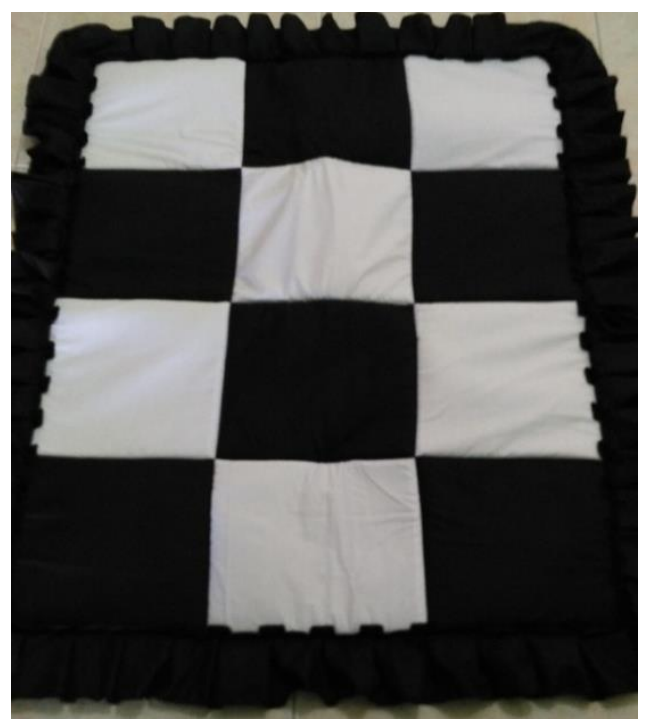

Gambar 4. Media lingkungan kontras (tikar bayi) 
Sri Hartati, Zulminiati. PELATIHAN PENGEMBANGAN MEDIA PEMBELAJARAN STIMULASI SENSORI VISUAL BAGI GURU PAUD DI KECAMATAN BATANG ANAI. Early Childhood Vol. 2 No. 2b, November 2018



Gambar 5. Media lingkungan kontras (mainan gantung)

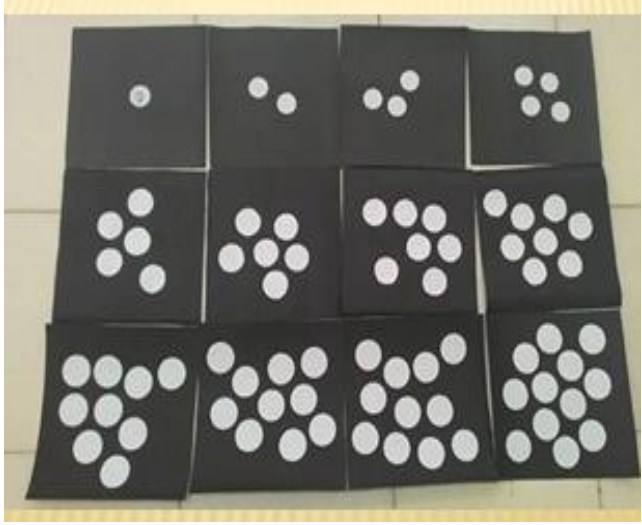

Gambar 6. Media kartu bit of intelegence (kartu bilangan sederhana)

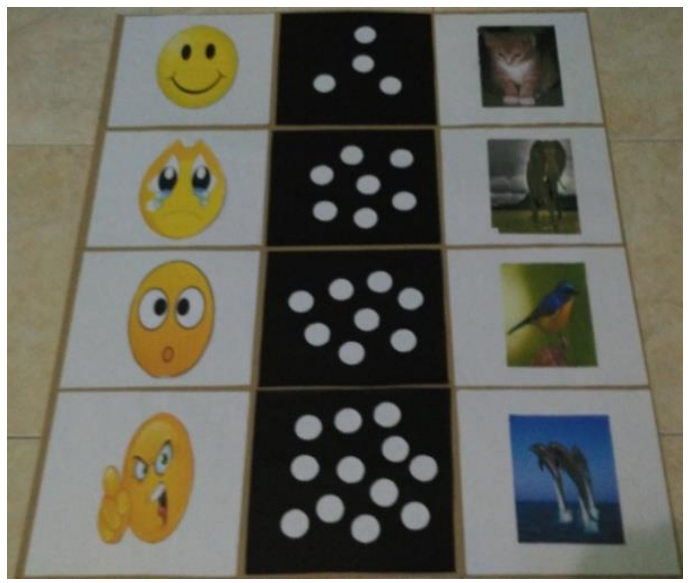

Gambar 7. Media kartu bit of intelegence (bilangan sederhana dan gambar)

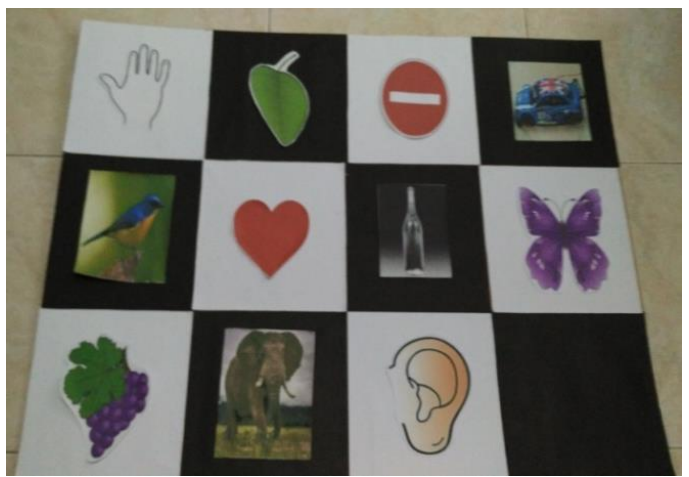

Gambar 8. Media flashcard (gambar)

Hasil pembuatan media stimulasi sensori visual yang telah dilakukan bagi guru PAUD di kecamatan Batang Anai Kabupaten Padang Pariaman telah menunjukkan keberhasilan dalam membuat media sensori visual berupa media lingkungan berkontras seperti tikar bayi dan mainan gantungan, kartu bit of intelegence seperti kartu bilangan sederhana dan kartu bilangan bergambar, media flashcard berupa gambar.

Keberhasilan ini cukup menggembirakan karena salah satu tujuan pengembangan menurut Mulyasa (2011) adalah memberikan kesempatan kepada guru untuk berimprovisasi dalam melakukan tindakan pembelajaran yang direncanakan secara tepat waktu dan sasarannya.

Dengan kemampuan yang dimiliki guru dalam membuat media pembelajaran sensori visual bagi guru PAUD di kecamatan Batang Anai Kabupaten Padang Pariaman ini akan memperlancar dan membantu guru dalam menyelenggarakan Pendidikan Anak Usia Dini di masa yang akan datang. 


\section{SIMPULAN}

Berdasarkan hasil pelaksanaan pelatihan dengan judul "Pelatihan Pengembangan Media Pembelajaran Stimulasi Sensori Visual Bagi Guru PAUD di Kecamatan Batang Anai Kabupaten Padang Pariaman" tahun 2018, maka memberikan rumusan hasil pelatihan dalam simpulan berikut ini:

1. Pelatihan diikuti oleh 30 peserta berasal dari para guru PAUD dari beberapa PAUD yang berada di Kecamatan Batang Anai Kabupaten Padang Pariaman.

2. Pelaksanaan pelatihan berlangsung sangat dinamis, antusias, dan bersemangat.

3. Peserta pengabdian telah mendapatkan pengetahuan dan keterampilan tentang pembuatan media lingkungan berkontras, kartu bit of intelegens, flashcard.

Saran penulis pada kegiatan pelatihan ini adalah agar pengetahuan dan keterampilan yang diperoleh peserta pengabdian diharapkan dapat ditularkan kepada guru-guru yang ada di kecamatan Batang Anai yang belum mendapatkan pelatihan. Penulis juga menyarankan agar pembuatan media visual yang telah dilakukan dapat dilaksanakan di masa yang akan datang.

DAFTAR PUSTAKA

Arikunto, Suharsimi. 2006. Prosedur Penelitian Suatu Pendekatan Praktek. Jakarta: PT. Rineka Cipta.
Asyhar, Rayandra. 2011. Kreatif Mengembangkan Media Pembelajaran. Jakarta:

Gaung Persada Press Jakarta Emzir. 2012. Metodologi Penelitian

Pendidikan. Jakarta: Rajawali Pers.

Mardalis. 2003. Metode penelitian Suatu Pendekatan Proposal. Jakarta: PT. Bumi Aksara.

Sugiyono. (2010). Memahami Penelitian Kuantitatif, Kualitatif dan $R \& D$. Bandung: Alfabeta. 